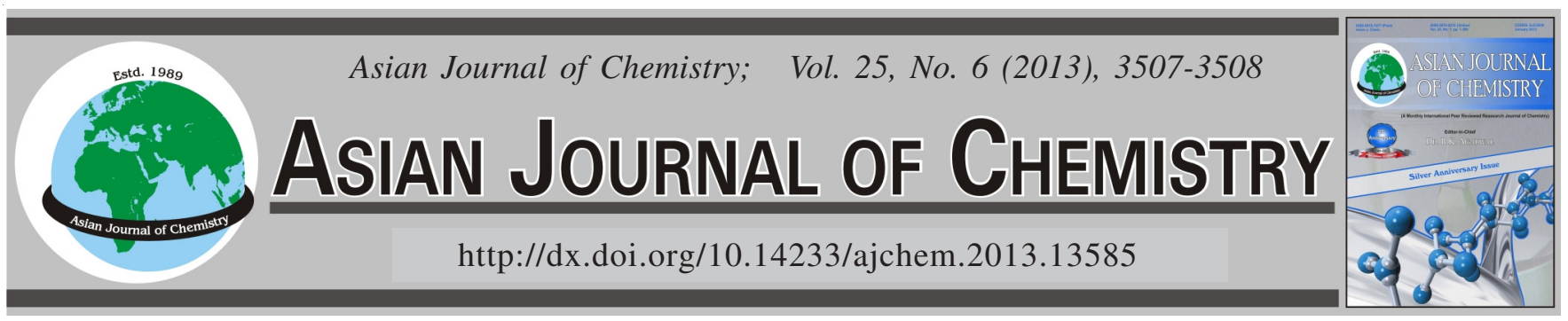

NOTE

\title{
Free Radical Scavenging Activities of $\beta$-Sitosterol Extracted from Abies yuanbaoshanensis
}

\author{
RuiJe He ${ }^{1}$, Biqun Zou ${ }^{2}$, Hong Fang ${ }^{1}$, Ye Zhang ${ }^{1,2}$ and Yingrui $\mathrm{Wu}^{1, *}$
}

${ }^{1}$ Guangxi Key Laboratory of Functional Phytochemicals Research and Utilization, Guangxi Institute of Botany, Guilin 541006, P.R. China ${ }^{2}$ Department of Chemistry, Guilin Normal College, Guangxi 541001, P.R. China

*Corresponding author: Fax: +86 77 32806321; Tel: +86 77 32823285; E-mail: wuyingrui2012@ 126.com

(Received: 13 February 2012;

Accepted: 28 December 2012)

AJC-12628

From Abies yuanbaoshanensis, $\beta$-sitosterol was isolated and purified by column chromatography. The free radical scavenging activities of $\beta$-sitosterol were evaluated against DPPH, ABTS and hydroxyl radicals, respectively. The results showed that all $\mathrm{IC}_{50}$ of $\beta$-sitosterol were much lower than the standard value $10 \mathrm{mg} / \mathrm{mL}$, demonstrating good radical scavenging activities of $\beta$-sitosterol.

Key Words: Abies yuanbaoshanensis, $\beta$-Sitosterol, Free radical scavenging activity.

Free radical scavengers or antioxidants are currently forged as the drug candidates to counter many diseases, such as drug-associated toxicity, inflammation, atherogenesis and aging in aerobic organisms ${ }^{1-3}$. Thus the significance of free radicals in the pathogenesis of various diseases has attracted considerable interest. Minor dietary compositions have been considerably deemed to combat the ill effects of free radicals. In addition, since that what may be learn from natural plants could overcome the toxicity problem of synthetic radical scavengers or antioxidants, so isolation of natural radical scavengers or antioxidants from natural plants has become a popular method.

Abies yuanbaoshanensis, which distributed in Rongshui county in Guangxi Province of China, is a peculiar endangered precious plant. The pharmacological research has showed that it possess of wide biological activities ${ }^{4}$, including antitumor, antibacterial, antifungal, antiinflammatory and antitussive activities. Previous studies have indicated that various diseases such as antitumor, antibacterial and antifungal are characteristically associated with free radicals and $\operatorname{ROS}^{5}$. It is possible that some constitutes of Abies yuanbaoshanensis should get good free radical scavenging activities. So herein the extraction and radical-scavenging activities of Abies yuanbaoshanensis was studied.

Abies yuanbaoshanensis were collected from Rongshui county of Guangxi Zhuang Autonomous Region in China, in July 2009 and verified by Prof. Zong-Ming Su. The air-dried needles and stems of Abies yuanbaoshanensis $(10 \mathrm{Kg})$ was extracted with $95 \%$ ethanol $(50 \mathrm{~L} \times 3$, each 7 days $)$ at room temperature and the combined extracts were concentrated in vacuum to give a residue $(450 \mathrm{~g})$, which was suspended in the water and re-extracted with petroleum ether, ethyl acetate successively to get three fractions. The petroleum ether extract (150 g) was subjected to column chromatography on silica-gel eluting with petroleum ether/ethyl acetate (100:0$50: 50, \mathrm{v} / \mathrm{v})$ to give 9 fractions. The petroleum ether/ethyl acetate 10:1 fraction ( $8 \mathrm{~g}$ ) was further purified by silica-gel column chromatography developing with petroleum ether/ $\mathrm{CHCl}_{3}$ /acetone (70:18:1) and a white needle crystals of $\beta$ sitosterol (960 mg) was obtained. The flow diagram was shown in Fig. 1. m.p. $135-137^{\circ} \mathrm{C} .{ }^{1} \mathrm{H}$ NMR (500 MHz, $\left.\mathrm{CDCl}_{3}\right)$ : $\delta 5.35$ (1H, br, d, $J=4.8 \mathrm{~Hz}, \mathrm{H}-6), 3.50$ (1H, m, H-3), $1.01(3 \mathrm{H}$, $\left.\mathrm{s}, \mathrm{CH}_{3}-19\right), 0.94\left(3 \mathrm{H}, \mathrm{d}, J=8.0 \mathrm{~Hz}, \mathrm{CH}_{3}-21\right), 0.85(3 \mathrm{H}, \mathrm{d}, J=8.0$ $\left.\mathrm{Hz}, \mathrm{CH}_{3}-29\right), 0.82$ (3H, d, $\left.J=7.6 \mathrm{~Hz}, \mathrm{CH}_{3}-26\right), 0.80$ (3H, d, $J=$ $\left.7.6 \mathrm{~Hz}, \mathrm{CH}_{3}-27\right), 0.67$ (3H, s, $\left.\mathrm{CH}_{3}-18\right) .{ }^{13} \mathrm{C} \mathrm{NMR}(125 \mathrm{MHz}$, $\left.\mathrm{CDCl}_{3}\right): \delta 37.2(\mathrm{C}-1), 31.6(\mathrm{C}-2), 71.6(\mathrm{C}-3), 42.3(\mathrm{C}-4), 140.7$ (C-5), 121.7 (C-6), 31.7 (C-7), 31.9 (C-8), 50.1 (C-9), 36.5 (C10), 21.1 (C-11), 39.6 (C-12), 42.3 (C-13), 56.6 (C-14), 24.3 (C-15), 28.2 (C-16), 56.2 (C-17), 11.8 (C-18), 19.8 (C-19), 36.4 (C-20), 18.8 (C-21), 33.7 (C-22), 26.0 (C-23), 45.4 (C24), 29.1 (C-25), 19.5 (C-26) 19.2 (C-27), 23.0 (C-28), 12.0 (C-29). The above data were consistent with $\beta$-sitosterol (Fig. 2) according with literature ${ }^{6}$.

In vitro antioxidant activities were measured against $\mathrm{DPPH}^{6}, \mathrm{ABTS}^{+7}$ and hydroxyl radicals ${ }^{8}$, respectively, according to the literatures ${ }^{6-9}$ with a little modification. The values of $\mathrm{IC}_{50}$, the effective concentration at which $50 \%$ of the radicals were scavenged, were calculated to evaluate the antioxidant 


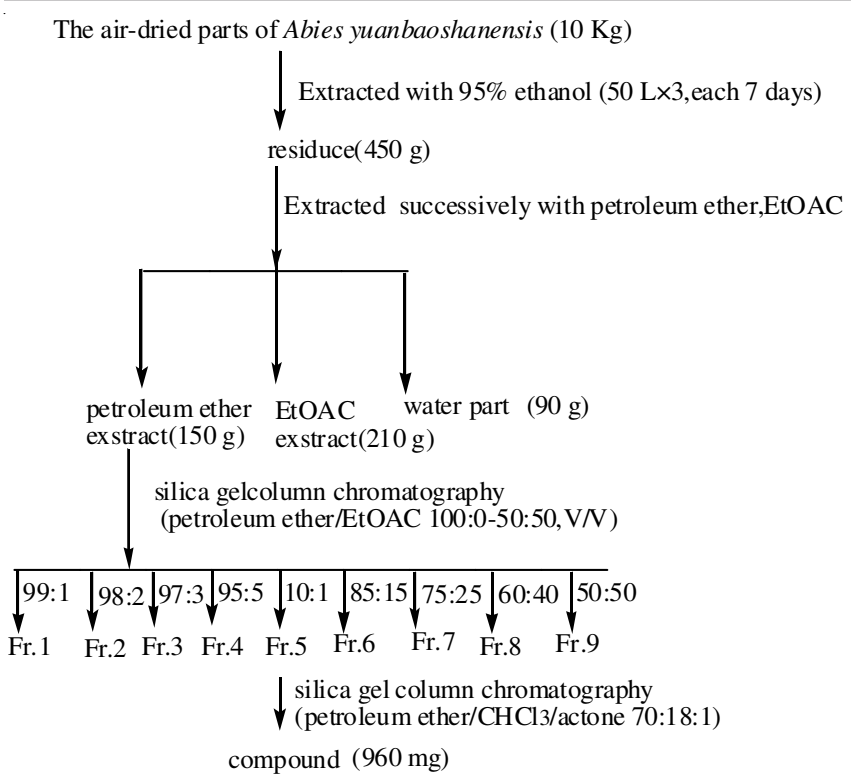

Fig. 1. Flow diagram of the optimal process

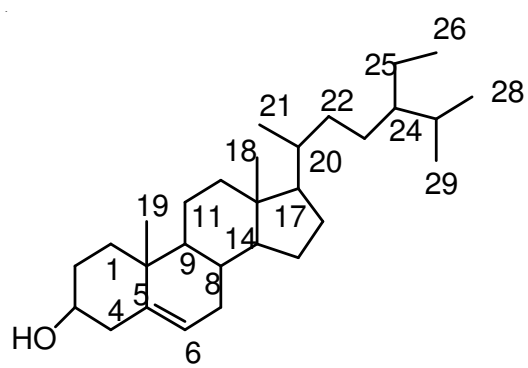

Fig. 2. Structure of $\beta$-sitosterol

activities. A lower $\mathrm{IC}_{50}$ value indicated greater antioxidant activity. $\mathrm{IC}_{50}$ values of lower than $10 \mathrm{mg} / \mathrm{mL}$ usually implied effective activities in antioxidant properties ${ }^{6}$. The tested results were shown in Fig. 3 (Table-1).

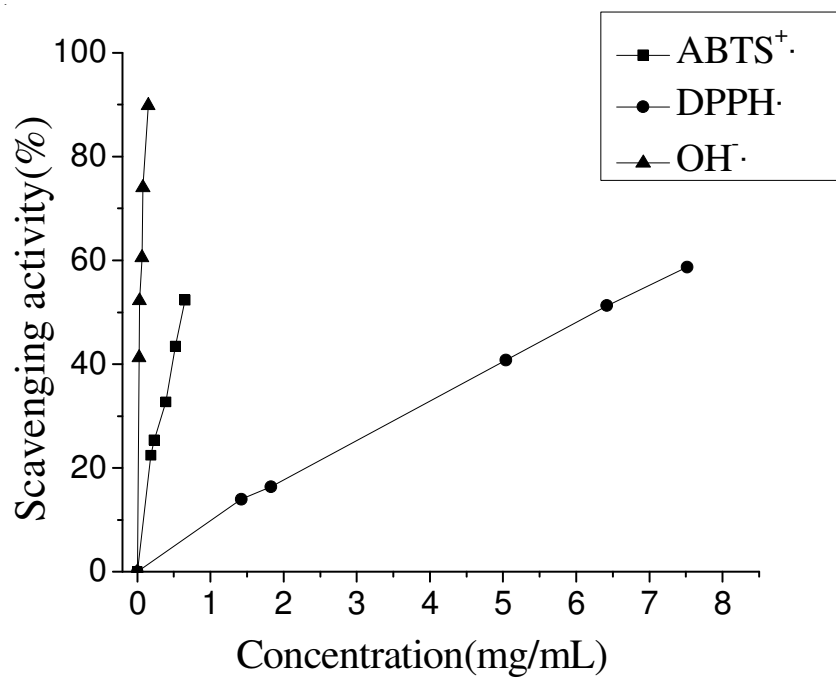

Fig. 3. Radical scavenging activities of $\beta$-sitosterol from Abies yuanbaoshanensis. Values are means \pm SD of three determinations. $p<0.05$, when compared with control

\begin{tabular}{cccc}
\multicolumn{4}{c}{ TABLE-1 } \\
& \multicolumn{1}{c}{$\begin{array}{c}\mathrm{IC}_{50}(\mathrm{mg} / \mathrm{mL}) \text { OF THE } \beta \text {-SITOSTEROL } \\
\text { FROM Abies yuanbaoshanensis }\end{array}$} \\
\hline $\mathrm{IC}_{50}(\mathrm{mg} / \mathrm{mL})$ & $\mathrm{DPPH}^{\bullet}$ & ABTS $^{\bullet}$ & $\mathrm{OH}^{\bullet}$ \\
\hline$\beta$-Sitosterol & 6.298 & 0.629 & 0.03 \\
\hline
\end{tabular}

DPPH radical scavenging activity evaluation, a classical assay in radical scavenging activity studies, could offer rapid techniques for screening the radical scavenging activity of the antioxidants or radical scavenger. As showed in Fig. 3 (Table-1), $\mathrm{IC}_{50}$ of $\beta$-sitosterol in DPPH assay was found to be $6.298 \mathrm{mg} / \mathrm{mL}$, which was evidently lower than the standard value $10 \mathrm{mg} / \mathrm{mL}^{6}$, indicating that $\beta$-sitosterol has good potent inhibition of DPPH radical.

$\mathrm{ABTS}^{+}$radical evaluation assay is another conventional and simple tool for determining the radical activity of hydrogen-donating and chain breaking radical scavengers ${ }^{7}$. As can be seen in Fig. 3 (Table-1), IC I0 $_{50}$ of $\beta$-sitosterol on $\mathrm{ABTS}^{+}$ radical was found to be $0.629 \mathrm{mg} / \mathrm{mL}$ and much lower than 10 $\mathrm{mg} / \mathrm{mL}^{6}$, demonstrating its good potent inhibition of $\mathrm{ABTS}^{+}$ radical.

The radical scavenging activities were also tested in the present study using hydroxyl radicals generated by Fenton reagent ${ }^{9}$. As shown in Fig. 3 (Table-1), $\beta$-sitosterol exhibited good activity in an amount dependent manner and its $\mathrm{IC}_{50}$ was found to be $0.03 \mathrm{mg} / \mathrm{mL}$, which was much lower than 10 $\mathrm{mg} / \mathrm{mL}^{6}$, indicating its good radical scavenging activities on hydroxyl radicals.

\section{Conclusion}

$\beta$-Sitosterol was extracted and isolated from Abies yuanbaoshanensis and it was found to get good radical scavenging activity on DPPH, $\mathrm{ABTS}^{+}$and hydroxyl radicals.

\section{ACKNOWLEDGEMENTS}

This study was supported by Natural Science of Guangxi fund project (GuiKe can 0832021, 1123006-4), Plant Institute of Guangxi Basic Business Expenses Project (GuiZhi industry 10008 and 11009), the Fund of Guangxi Key Laboratory of Functional Phytochemicals Research and Utilization (No. FPRU2011-6).

\section{REFERENCES}

1. B.N. Ames, M.K. Shigenaga and T.M. Hagen, Proc. Natl. Acad. Sci. (USA), 90, 7915 (1993).

2. A.A. Eurton and S. Fairhurst, Crit. Rev. Toxicol., 18, 27 (1987).

3. H.L. Wang, Z.Y. Yang and B.D. Wang, Transition Met. Chem., 31, 470 (2006).

4. X.W. Yang, S.M. Li, Y.H. Shen and W.D. Zhang, Chem. Biodivers, 5, 56-81 (2008)

5. Y.L. Lee, M.T. Yen and J.L. Mau, Food Chem., 104, 1 (2007).

6. G. Ghosh, B.B. Subudhi, D. Mishra, P.S. Kumar and S.K. Mishra, Asian J. Chem., 23, 1341 (2011).

7. L.P. Leong and G. Shui, Food Chem., 76, 69 (2002)

8. T.W. Stief, Med. Hypotheses, 60, 567 (2003).

9. Y.M. Pan, X.P. Zhang, H.S. Wang, Y. Liang, J.C. Zhu, H.Y. Li, Z. Zhang and Q.M. Wu, Food Chem., 105, 1518 (2007). 